\title{
Optimizing a reliable ex vivo human blood model to analyze expression of Staphylococcus epidermidis genes
}

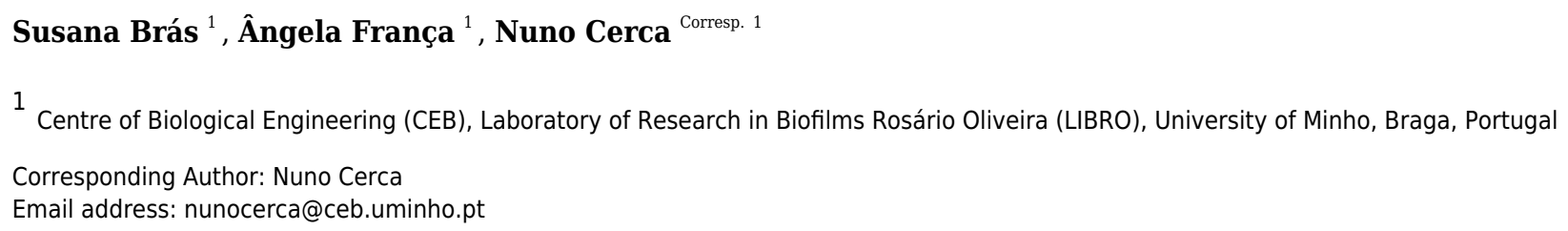

Human blood is often used as an ex vivo model to mimic the environment encountered by pathogens inside the host. A significant variety of experimental conditions has been reported. However, optimization strategies are often not described. This study aimed to evaluate key parameters that are expected to influence Staphylococcus epidermidis gene expression when using human blood ex vivo models. Our data confirmed that blood antimicrobial activity was dependent on initial bacterial concentration. Furthermore, blood degradation over time resulted in lower antimicrobial activity, with a $2 \%$ loss of leukocytes viability correlating with a 5 -fold loss of antimicrobial activity against $S$. epidermidis. We further demonstrated that the volume of human blood could be reduced to as little as 0.18 $\mathrm{mL}$ without affecting the stability of gene expression of the tested genes. Overall, the data described herein highlight experimental parameters that should be considered when using a human blood ex vivo model for $S$. epidermidis gene expression analysis. 


\section{Optimizing a reliable ex vivo human blood model to} 2 analyze expression of Staphylococcus epidermidis 3 genes

4 Susana Brás, Ângela França, Nuno Cerca*

5 Centre of Biological Engineering (CEB), Laboratory of Research in Biofilms Rosário Oliveira

6 (LIBRO), University of Minho, Campus de Gualtar, Braga, Portugal.

8 Corresponding author*:

9 Nuno Cerca

10 Centre of Biological Engineering, LIBRO - Laboratory of Research in Biofilms Rosário Oliveira, 11 University of Minho, Campus de Gualtar, 4710-057, Braga, Portugal.

12 Tel.: +351 25360443 , fax: +351253678986

13 Email address: nunocerca@ceb.uminho.pt

\section{Abstract}

Human blood is often used as an ex vivo model to mimic the environment encountered by pathogens inside the host. A significant variety of experimental conditions has been reported. However, optimization strategies are often not described. This study aimed to evaluate key parameters that are expected to influence Staphylococcus epidermidis gene expression when using human blood ex vivo models. Our data confirmed that blood antimicrobial activity was dependent on initial bacterial concentration. Furthermore, blood degradation over time resulted in lower antimicrobial activity, with a $2 \%$ loss of leukocytes viability correlating with a 5 -fold loss of antimicrobial activity against $S$. epidermidis. We further demonstrated that the volume of human blood could be reduced to as little as $0.18 \mathrm{~mL}$ without affecting the stability of gene expression of the tested genes. Overall, the data described herein highlight experimental parameters that should be considered when using a human blood ex vivo model for S. epidermidis gene expression analysis.

Keywords: Bacterial survival, ex vivo model, Gene expression, Human blood; Staphylococcus epidermidis, Volume of human blood. 
32

33

34

35

36

37

\section{Introduction}

Staphylococcus epidermidis is a commensal inhabitant of healthy human skin and mucosae that can cause important infections, such as medical device-associated bloodstream infections (Otto 2009). Due to the clinical relevance of these infections, it is important to understand the strategies employed by $S$. epidermidis to evade the host immune system response. In order to better comprehend how S. epidermidis adapts to the host, gene expression studies are often conducted under conditions that try to mimic the in vivo environment (Loza-Correa. et al. 2019). Human blood ex vivo models have contributed to a better understanding of how pathogens survive in human blood, by evaluating the transcriptional response during incubation in human blood, as well as, by exploring host-pathogen interactions. These models are relatively easy to implement, have been reported in many clinically relevant microorganisms, including S. epidermidis (França et al. 2014; Qin et al. 2017), Staphylococcus aureus (Malachowa et al. 2011),Neisseria meningitidis (Echenique-Rivera et al. 2011; Nolte et al. 2002), Streptococcus agalactiae (Mereghetti et al. 2008), Enterococcus faecalis (Vebo et al. 2009) and Candida albicans (Fradin et al. 2005; Fradin et al. 2003; Hunniger et al. 2014).

However, the implementation of these models lacks often do not describe optimization steps and, not surprisingly, a significant variety of experimental set-up conditions have been reported (Fradin et al. 2003; França et al. 2014a; Hedman et al. 2012; Qin et al. 2017). Because different experimental designs can greatly influence experimental outcomes, we became interested in evaluating key parameters that can compromise $S$. epidermidis gene expression studies when using a human blood ex vivo model. To achieve this goal, we evaluated the initial bacterial concentration and the volume of human blood in the co-incubation assays, as well as leukocyte viability after blood collection, and assessed bacterial survivability and gene expression under a human ex vivo blood model.

\section{Material and methods}

\section{Bacterial strains and growth conditions}

S. epidermidis PT12003, isolated from a patient with a central catheter after stomach surgery (Freitas et al. 2018), was used in this study. One single colony was inoculated into $2 \mathrm{~mL}$ of Tryptic Soy Broth (TSB) (Liofilchem, Teramo, Italy) and incubated overnight at $37^{\circ} \mathrm{C}$ and at $120 \mathrm{rpm}$ (ES20 Shaker-Incubator, Biosan, Riga, Latvia). Planktonic cultures were started by adjusting the 
62 optical density at $640 \mathrm{~nm}\left(\mathrm{OD}_{640 \mathrm{~mm}}\right)$, to $0.050( \pm 0.005)$ in $10 \mathrm{~mL}$ of TSB and grown, in a $25 \mathrm{~mL}$

63 flask, for $6 \mathrm{~h}$ at $37^{\circ} \mathrm{C}$ and at $120 \mathrm{rpm}$. The suspension was then washed once and resuspended in $0.9 \% \mathrm{NaCl}$. Before further experiments, the $\mathrm{OD}_{640 \mathrm{~nm}}$ of bacterial suspension was adjusted to $2.7 \mathrm{in}$ order to obtain $1 \times 10^{9} \mathrm{CFU} / \mathrm{mL}$.

\section{Human Blood collection}

Peripheral blood was collected by venipuncture from Portuguese healthy adult volunteers with an age range between 25-40 ( 7 female and 4 male donors), not taking antibiotics or anti-inflammatory medication within the previous 14 days. Blood was drawn using one of the following anticoagulant tubes: $\mathrm{K}_{3}$ EDTA (Vacuette, Greiner Bio-one, Kremsmünster, Austria), sodium citrate (Vacuette, Greiner Bio-one, Kremsmünster, Austria) or lithium heparin (Becton Dickinson, NJ, USA). Blood was collected under a protocol approved by the Institutional Review Board of the University of Minho (SECVS 002/2014 (ADENDA)), which is in strict accordance with the Declaration of Helsinki and Oviedo Convention. All donors gave written informed consent to have blood taken.

\section{The influence of anticoagulants on bacterial growth}

In order to explore the effect of different anticoagulants on bacterial growth, TSB (Liofilchem, Teramo, Italy) was added to the different blood collection tubes and was gently inverted 5 to 8 times, before being transferred to a $25 \mathrm{~mL}$ flask. Planktonic bacteria obtained as described above was inoculated into TSB with the different anticoagulants, at a final concentration of $10^{7} \mathrm{CFU} / \mathrm{mL}$. A negative control was included by inoculating bacteria in TSB without anticoagulants. Bacterial suspensions were incubated for $24 \mathrm{~h}$ at $37^{\circ} \mathrm{C}$ and at $120 \mathrm{rpm}$ (ES-20 Shaker-Incubator). Bacterial growth was determined by CFU quantification by taking aliquots every $2 \mathrm{~h}$. The aliquots were serially diluted and plated on TSB agar using the (Miles et al. 1938) and incubated at $37^{\circ} \mathrm{C}$. At least two independent experiments with two technical replicates were performed.

\section{The ability of bacteria to survive in human blood}

For the evaluation of the ability of bacteria to survive in human blood, $0.1 \mathrm{~mL}$ of different concentrations of exponentially growing bacteria, were added to $0.9 \mathrm{~mL}$ of human blood in $2 \mathrm{~mL}$ tubes, to obtain final concentrations of $10^{8}, 10^{7}, 10^{6}, 10^{5}$ or $10^{4} \mathrm{CFU} / \mathrm{mL}$ and incubated at $37^{\circ} \mathrm{C}$, at $80 \mathrm{rpm}$, for up to $8 \mathrm{~h}$. Four and $8 \mathrm{~h}$ after incubation, the enumeration of bacteria was determined by CFU counting, as described above. The number of CFU/mL immediately (i.e., less than 2 min) 
91 after incubation with blood was used as a control to calculate the percentage of survival. This

92 experiment was performed five independent times, using blood from five different donors.

93

94

95

96

97

\section{Viability of human blood leukocytes over time}

Human blood leukocytes viability after collection was used as an indicator of blood degradation over time. Whole blood was collected and incubated for up to $8 \mathrm{~h}$ at $37^{\circ} \mathrm{C}$ and $80 \mathrm{rpm}$ (PSU-10i, Biosan). At time points 0 (immediately after collection), $4 \mathrm{~h}$ and $8 \mathrm{~h}, 2 \mathrm{~mL}$ of whole blood was collected and incubated with $5 \mathrm{~mL}$ of red blood cells (RBC) lysis buffer (Alfa Aesar, Karlsruhe, Germany). The suspension was mixed by carefully inverting the tubes and then incubated at room temperature for $10 \mathrm{~min}$. The reaction was stopped by adding $15 \mathrm{~mL}$ of phosphate buffered saline (PBS) (Gibco, MA, USA). Leukocytes were harvested by $10 \mathrm{~min}$ centrifugation at $300 \mathrm{~g}$ and $4^{\circ} \mathrm{C}$, and a new RBC lysis cycle was performed to lyse residual red blood cells. Leukocytes were then suspended in $0.5 \mathrm{~mL}$ of PBS and cells viability determined through flow cytometry (EC800, Sony Biotechnologies Inc, CA, USA), using propidium iodide staining ( $5 \mu \mathrm{g} / \mathrm{mL}$, Sigma, MO, USA). This experiment was performed three independent times, using blood from different donors. Representative flow cytometry plots are presented in Supplementary Fig. S1.

\section{The impact of time after blood collection on bacterial survival in human blood}

Whole blood was collected and an aliquot $(0.9 \mathrm{~mL})$ was immediately taken and mixed in a $2 \mathrm{~mL}$ tube with $0.1 \mathrm{~mL}$ of $S$. epidermidis, to obtain a final bacterial concentration of $10^{5} \mathrm{CFU} / \mathrm{mL}$, and incubated at $37^{\circ} \mathrm{C}$ and $80 \mathrm{rpm}$ for $4 \mathrm{~h}$. . The remaining blood was kept under the same temperature and agitation conditions for $4 \mathrm{~h}$. After this time, a new $0.9 \mathrm{~mL}$ aliquot of blood was taken and a second incubation with $0.1 \mathrm{~mL}$ of $S$. epidermidis was performed for another $4 \mathrm{~h}$, in a new $2 \mathrm{~mL}$ tube. Bacteria was quantified by CFU counting, as described above. This experiment was performed three independent times, using blood from three different donors.

\section{S. epidermidis gene expression assays}

Three unrelated genes were selected as probes for assessing gene expression stability: SERP_RS11970, SERP_RS10985 and SERP_RS08870. Two different experimental conditions were tested: (i) the utilization of different anticoagulants on the collection tubes and (ii) the 
121 reduction of the volume of blood used during the co-incubation assays (total incubation volume of

$1221 \mathrm{~mL}, 0.6 \mathrm{~mL}, 0.5 \mathrm{~mL}$, and $0.2 \mathrm{~mL}$ ). Blood samples were transferred into $2 \mathrm{~mL}$ tubes and, then,

123 bacteria were added to each tube to obtain a final concentration of $10^{8} \mathrm{CFU} / \mathrm{mL}$. The tubes were

124 incubated for $2 \mathrm{~h}$ at $37^{\circ} \mathrm{C}$ and $80 \mathrm{rpm}$ (PSU-10i). After the co-incubation period, samples were

125 sonicated for 5s at 33\% amplitude (Cole-Parmer 750- Watt Ultrasonic Homogenizer 230 VAC,

126 IL, USA) to lyse eukaryotic cells. Total RNA isolation, complementary DNA synthesis (cDNA)

127 and quantitative PCR (qPCR) were performed as previously optimized (França et al. 2012), with

128 minor modifications. In brief, after mechanical and chemical lysis of bacterial cells, total RNA 129 was purified using EZNA total RNA kit (Omega Biotek, GA, USA). Genomic DNA was degraded

130 by DNase I (Thermo Scientific, MA, USA) and cDNA synthesized, from 200 ng of total RNA, by

131 RevertAid M-MuLV reverse transcriptase (Thermo Fisher Scientific) and using random primers

132 (NZYTech, Lisboa, Portugal) as priming strategy. Finally, qPCR was prepared by mixing $2 \mu \mathrm{L}$ of

133 1:100 diluted cDNA with $5 \mu \mathrm{L}$ of Xpert Fast SYBR (Grisp, Porto, Portugal), $0.5 \mu \mathrm{L}$ of each

134 forward and reverse primers at $0.5 \mu \mathrm{M}$ and $2 \mu \mathrm{L}$ of nuclease-free water. The run was completed

135 in a CFX96 ${ }^{\mathrm{TM}}$ thermal cycler (Bio-Rad, CA, USA) with the following cycling parameters: 3 min

136 at $95^{\circ} \mathrm{C}$ followed by 40 cycles of $5 \mathrm{~s}$ at $95^{\circ} \mathrm{C}$ and $25 \mathrm{~s}$ at $60^{\circ} \mathrm{C}$. The primers used were designed

137 using Primer3 software (Koressaar \& Remm 2007; Untergasser et al. 2012) and synthesized at

138 Metabion (Steinkirchen, Germany). Primers sequences, size of the amplicon and reaction

139 efficiency are presented in Table 1. The quantification of the transcripts for each gene under study 140 was determined using $16 \mathrm{~S}$ rRNA as reference gene and by applying the delta $\mathrm{C}_{\mathrm{q}}$ method ( $\mathrm{E}^{\Delta \mathrm{Cq})}$, a

141 variation of the Livak method (Livak \& Schmittgen 2001), where $\Delta \mathrm{C}_{\mathrm{q}}=\mathrm{C}_{\mathrm{q}}$ (reference gene) - $\mathrm{C}_{\mathrm{q}}$

142 (target gene) and $\mathrm{E}$ is the experimentally determined reaction efficiency. Reaction efficiencies 143 were determined using the dilution method (Pfaffl 2004) at $60^{\circ} \mathrm{C}$.

\section{Statistical analysis}

145 Statistical analysis was carried out with GraphPad Prism Version 6 Trial (CA, USA). For 146 comparisons among different groups one-way or two-away ANOVA, with Tukey's comparisons 147 test, were used when appropriate (the tests used are detailed in the figure caption). $P<0.05$ was 148 considered significant. 


\section{Results and discussion}

150 Human blood ex vivo models have been developed to mimic bloodstream infections as an

151 affordable alternative to in vivo models (Echenique-Rivera et al. 2011; Malachowa et al. 2011;

152 Qin et al. 2017). During human blood collection, anticoagulants need to be used to prevent blood

153 clotting. It has been pointed out that different anticoagulants may influence the experimental

154 outcome (Freitas et al. 2008; Strobel \& Johswich 2018). The most commonly used anticoagulants

155 are heparin, citrate and EDTA (Engstad et al. 1997). Citrate and EDTA prevent blood from clotting

156 through binding free calcium ions (Strobel \& Johswich 2018), while heparin inhibits coagulation

157 by enhancing the activity of antithrombin III (Engstad et al. 1997). Herein, pilot experiments were

158 initially performed to determine the best anticoagulant for $S$. epidermidis gene expression analysis.

159 Thus, the influence of heparin, citrate, and EDTA was evaluated on bacterial growth and

160 transcription levels of the selected genes. As shown in Supplementary Fig.S2, EDTA, but not the

161 other tested anticoagulants, inhibited bacterial growth in the first $8 \mathrm{~h}$, eventually leading to bacterial

162 death, after $24 \mathrm{~h}$ of incubation. A similar effect was reported before in some strains of $N$.

163 meningitidis, when using citrate as anticoagulant (Strobel \& Johswich 2018) but in our

164 experimental setup, we did not observed any inhibitory effect regarding S. epidermidis growth. .

165 Interestingly, when analyzing bacterial gene expression no significant differences were found

166 among the different anticoagulants tested. Taken into consideration (i) these pilot results, (ii) the

167 availability and (iii) price difference between the anticoagulants tested, and previous experimental

168 results (França et al. 2014; Franca et al. 2016) we selected heparin for the remaining the

169 experiments.

170 An important issue related to human blood ex vivo models is the bacterial concentration used.

171 Although the quantity of microbes present in human blood during bacteremia is estimated to be up

172 to $10^{4} \mathrm{CFU} / \mathrm{mL}$ (Opota et al. 2015), often higher concentrations of bacteria have been used in

173 human blood ex vivo models (Askarian et al. 2017; França et al. 2014; Qin et al. 2017), mainly

174 due to the lack of sensitivity of many experimental methods to assess lower bacterial

175 concentrations (Bacconi; et al. 2014; Machado et al. 2013). For instance, it is known that for the

176 analysis of the transcriptomic response of bacteria, the initial bacterial concentration needs to be

177 significantly higher, to ensure a sufficient amount of RNA for downstream applications (Hedman

178 et al. 2012). To investigate the effect of different initial bacterial concentration on the ability of $S$.

179 epidermidis to survive in human blood, different bacterial concentrations $\left(10^{4}\right.$ to $\left.10^{8} \mathrm{CFU} / \mathrm{mL}\right)$ 
180 were used for the bacterial survival assays. After $4 \mathrm{~h}$ and $8 \mathrm{~h}$ of co-incubation, the percentage of 181 bacterial survival was determined (Figure 1). Since it is known that there is a significant source of 182 experimental variability when working with human samples, due to the inherent traits of the donors

192

193

194

195

196

197

198

199

200

201

202

203

204

205

206

207

208

209

210 such as age (Eady et al. 2005), gender (Whitney et al. 2003) and the proportion of different blood cell populations (Cobb et al. 2005), this experiment was performed with blood from five different donors, to increase the significance of our results. Not surprisingly, the ability of S. epidermidis to survive in human blood was cell concentration dependent: the lower the inoculum, the higher the percentage of bacterial killing by human blood (Figure 1). Interestingly, after $4 \mathrm{~h}$ of co-incubation, cell death was observed in all tested bacterial concentrations but after $8 \mathrm{~h}$ of co-incubation, the higher concentration inocula presented higher cell density than at time zero. This suggests that over time, and when the bacterial inoculum was $10^{8} \mathrm{CFU} / \mathrm{mL}$, blood lost some antimicrobial activity leading to bacteria growth.

To confirm that longer blood incubation periods would result in lower antimicrobial activity, a second experiment was performed. For this assay, we selected a bacterial concentration of $10^{5}$ $\mathrm{CFU} / \mathrm{mL}$, taken in consideration the significant killing observed after $4 \mathrm{~h}$ of incubation (Figure 1). As shown in Figure 2A, the co-incubation of S. epidermidis with human blood after 4h, resulted in different bacterial killing rates, depending if the blood was used immediately or $4 \mathrm{~h}$ after collection: while $97 \%$ of bacterial was killed if blood was used immediately, only $84 \%$ of death was observed if we used blood $4 \mathrm{~h}$ after collection. It is well described that blood antimicrobial activity against $S$. epidermidis involves important components such as complement and leukocytes (Le et al. 2018). As such, to evaluate blood degradation, we assessed leukocytes viability right after blood collection, and also 4 and $8 \mathrm{~h}$ after collection. As shown in Figure 2B, right after blood collection, 3\% of leukocytes were already dead. This fact may be related to the process of collection and processing time of human blood (Ferrante \& Thong 1980). The results also showed that $4 \mathrm{~h}$ after blood collection, cell death rate was slightly increased to $5 \%$ and then to $15 \%$ after $8 \mathrm{~h}$. Interestingly, a $2 \%$ reduction in leukocyte viability (from 3 to $5 \%$ ) was correlated with 13\% reduction in antimicrobial activity (from 97\% to 84\%). However, it should be noted that blood degradation over time will likely affect other important components that were not quantified herein, such as complement (Nordahl et al. 2004). As such, based on these results, it's not possible to determine which exact mechanism involved in blood degradation contributed to the effective 
211 loss of antimicrobial activity over time. Nevertheless, our data clearly confirms that longer waiting

212 times after blood collection will contribute to blood degradation. This fact is important to consider

213 when planning ex vivo experiments with blood, as it may have substantial consequences on the

214 results obtained, especially if a higher bacterial inoculum is needed, such as when performing

215 RNA-sequencing (França et al. 2014; Franca et al. 2016; Malachowa et al. 2011; Qin et al. 2017).

216 Some studies have used human blood ex vivo model with incubation periods up to 24h (Nolte et

217 al. 2002). However, as shown by our results, $24 \mathrm{~h}$ is an extensive period of incubation which may

218 yield higher blood degradation and, as such, should be avoided when determining bacterial

219 survival studies in human blood. Blood degradation can occur when research laboratories are not

220 physically close to human blood collecting centers, and this should also be taken into consideration

221 when planning experiments using human blood. A simple way to reduce this obstacle is to maintain

222 the blood using gentle agitation (Afonso et al. 2010).

223

224 Another important practical aspect when considering using human blood as an ex-vivo model is

225 the limitation of blood availability. As such, the ability to reduce the volume of blood per 226 experiment, without compromising the results, is of interest. When analyzing several published 227 gene expression studies, it was observed that different volumes of human blood, ranging from 0.2 $228 \mathrm{~mL}$ to $80 \mathrm{~mL}$ per experiment, have been reported (Echenique-Rivera et al. 2011; Hedman et al. 229 2012; Hunniger et al. 2014; Mereghetti et al. 2008; Qin et al. 2017). As the long-term goal of our 230 research group is to assess global transcriptomic changes occurring with $S$. epidermidis gene 231 expression, using ex vivo blood models, there was interest in determining if reducing the volume 232 of blood in the co-incubation assays down to $0.18 \mathrm{~mL}$ had a detrimental effect on the stability of 233 gene transcription. The starting volume was $0.9 \mathrm{~mL}$, in order to compare with our previous data 234 obtained using RNA-seq (França et al. 2014). For this assay, we selected a bacterial concentration 235 of $10^{8} \mathrm{CFU} / \mathrm{mL}$ to ensure a sufficient amount RNA that would be needed for future RNA236 sequencing studies (Hedman et al. 2012). The transcription of three unrelated genes was assessed.

237 One of the selected genes was sepA (SERP_RS08870), which codifies a protease that plays an 238 important role in bacterial immune invasion through the degradation of antimicrobial peptides 239 produced by the host (Lai et al. 2007). The two other selected genes were SERP_RS11970, a gene 240 that codifies a major facilitator superfamily and $S E R P \_R S 10985$, a universal stress protein. As 241 shown in Figure 3, no significant differences were found in the expression of the selected genes 
242 using, in any of the different volumes of human blood tested. Noteworthy, a volume of blood as

243 low as $0.18 \mathrm{ml}$ per reaction could be used without impacting the transcription of the selected genes.

244 Nevertheless, we acknowledge that a limitation of this study was the fact that the selected genes

245 had relative expressions (to the $16 \mathrm{~S}$ ribosomal RNA) between $\sim 10-3$ and $\sim 10-7$.. While this is a

246 very large dynamic range, we can't exclude the possibility that very low expressing genes $(\leq 10-8)$

247 could potentially be affected differently.

248

249 Conclusion

250 There remains a great deal of work to be done in clarifying the factors that contribute to $S$. 251 epidermidis survival and adaptation to blood, which contribute to the evasion from the host 252 immune system. The improvement of human blood ex vivo models will contribute to 253 standardization of experimental conditions and produce a more reliable experimental setup and, 254 consequently, contribute to obtain results with higher clinical relevance. The findings from the 255 study are of technical importance for future studies since it highlights key parameters that should 256 be considered when using human blood as an ex vivo model for the analysis of the gene expression 257 of S. epidermidis, in particular, the possibility of using low volume of blood per reaction, without 258 compromising the experimental results, at least in regard to the parameters tested herein.

\section{Conflict of interest}

261 The authors declare that they have no conflict of interest.

\section{Funding information}

263 This work was supported by the Portuguese Foundation for Science and Technology (FCT) by the 264 funded project PTDC/BIA-MOL/29553/2017, under the scope of COMPETE2020 [POCI-010145-FEDER-02955 and by the strategic funding of unit UIDB/04469/2020 and by European funds under BioTecNorte operation [NORTE-01-0145-FEDER-000004 funded by European granted by a Doctoral Advanced Training [Norte 69-2015-15 funded by the European Social Fund under the scope of Norte2020. The funders had no role in study design, data collection and interpretation, or the decision to submit the work for publication. 
272

273

274

275

276

277

278

279

280

281

282

283

284

285

286

287

288

289

290

291

292

293

294

295

296

297

298

299

\section{References}

Afonso G, Scotto M, Renand A, Arvastsson J, Vassilieff D, Cilio CM, and Mallone R. 2010. Critical parameters in blood processing for T-cell assays: validation on ELISpot and tetramer platforms. Journal of Immunological Methods 359:28-36.

Askarian F, Uchiyama S, Valderrama JA, Ajayi C, Sollid JU, van Sorge NM, Nizet V, van Strijp JA, and Johannessen M. 2017. Serine-Aspartate Repeat Protein D Increases Staphylococcus aureus Virulence and Survival in Blood. Infection Immunology 85.

Bacconi; A, Gregory S. Richmond, Michelle A. Baroldi, Thomas G. Laffler, Lawrence B. Blyn, Heather E. Carolan, Mark R. Frinder, Donna M. Toleno, David Metzgar, Jose R. Gutierrez, Christian Massire, Megan Rounds, Natalie J. Kennel, Richard E. Rothman, Stephen Peterson, Karen C. Carroll, Teresa Wakefield, David J. Ecker, and Sampath R. 2014. Improved Sensitivity for Molecular Detection of Bacterial and Candida Infections in Blood. Journal of Clinical Microbiology 52:3164-3174.

Cobb JP, Mindrinos MN, Miller-Graziano C, Calvano SE, Baker HV, Xiao W, Laudanski K, Brownstein BH, Elson CM, Hayden DL, Herndon DN, Lowry SF, Maier RV, Schoenfeld DA, Moldawer LL, Davis RW, and Tompkins RG. 2005. Application of genome-wide expression analysis to human health and disease. Proceeding of the National Academic of Science of US A 102:4801-4806.

Eady JJ, Wortley GM, Wormstone YM, Hughes JC, Astley SB, Foxall RJ, Doleman JF, and Elliott RM. 2005. Variation in gene expression profiles of peripheral blood mononuclear cells from healthy volunteers. Physiological Genomics 22:402-411.

Echenique-Rivera H, Muzzi A, Del Tordello E, Seib KL, Francois P, Rappuoli R, Pizza M, and Serruto D. 2011. Transcriptome analysis of Neisseria meningitidis in human whole blood and mutagenesis studies identify virulence factors involved in blood survival. PLOS Pathogens 7:e1002027.

Engstad CS, Gutteberg TJ, and Osterud B. 1997. Modulation of blood cell activation by four commonly used anticoagulants. Thrombosis Haemostasis 77:690-696. 
300 Ferrante A, and Thong YH. 1980. Optimal conditions for simultaneous purification of 301 mononuclear and polymorphonuclear leucocytes from human blood by the Hypaque-Ficoll

302

303

304

305

306

307

308

309

310

311

312

313

314

315

316

317

318

319

320

321

322

323

324

325

326

327

328

329 method. Journal of Immunological Methods 36:109-117.

Fradin C, De Groot P, MacCallum D, Schaller M, Klis F, Odds FC, and Hube B. 2005. Granulocytes govern the transcriptional response, morphology and proliferation of Candida albicans in human blood: Neutrophils trigger C. albicans response. Molecular Microbiology 56:397-415.

Fradin C, Kretschmar M, Nichterlein T, Gaillardin C, d'Enfert C, and Hube B. 2003. Stage-specific gene expression of Candida albicans in human blood. Molecular Microbiology 47:1523-1543.

França A, Carvalhais V, Maira-Litrán T, Vilanova M, Cerca N, and Pier G. 2014. Alterations in the Staphylococcus epidermidis biofilm transcriptome following interaction with whole human blood. Pathogens and Disease 70:444-448.

França A, Freitas AI, Henriques AF, and Cerca N. 2012. Optimizing a qPCR Gene Expression Quantification Assay for S. epidermidis Biofilms: A Comparison between Commercial Kits and a Customized Protocol. PLOS ONE 7:e37480.

Franca A, Pier GB, Vilanova M, and Cerca N. 2016. Transcriptomic Analysis of Staphylococcus epidermidis Biofilm-Released Cells upon Interaction with Human Blood Circulating Immune Cells and Soluble Factors. Frontiers in Microbiology 7.

Freitas AI, Lopes N, Oliveira F, Bras S, Franca A, Vasconcelos C, Vilanova M, and Cerca N. 2018. Comparative analysis between biofilm formation and gene expression in Staphylococcus epidermidis isolates. Future Microbiology 13:415-427.

Freitas M, Porto G, Lima JL, and Fernandes E. 2008. Isolation and activation of human neutrophils in vitro. The importance of the anticoagulant used during blood collection. Clinical Biochemistry 41:570-575.

Hedman AK, Li MS, Langford PR, and Kroll JS. 2012. Transcriptional profiling of serogroup B Neisseria meningitidis growing in human blood: an approach to vaccine antigen discovery. PLOS ONE 7:e39718.

Hunniger K, Lehnert T, Bieber K, Martin R, Figge MT, and Kurzai O. 2014. A virtual infection model quantifies innate effector mechanisms and Candida albicans immune escape in human blood. PLoS Comput Biol 10:e1003479. 
330 Koressaar T, and Remm M. 2007. Enhancements and modifications of primer design program

331

332

333

334

335

336

337

338

339

340

341

342

343

344

345

346

347

348

349

350

351

352

353

354

355

356

357

358

359

360 Primer3. Bioinformatics 23:1289-1291.

Lai Y, Villaruz AE, Li M, Cha DJ, Sturdevant DE, and Otto M. 2007. The human anionic antimicrobial peptide dermcidin induces proteolytic defence mechanisms in staphylococci. Molecular Microbiology 63:497-506.

Le KY, Park MD, and Otto M. 2018. Immune Evasion Mechanisms of Staphylococcus epidermidis Biofilm Infection. Frontiers in Microbiology 9.

Livak KJ, and Schmittgen TD. 2001. Analysis of relative gene expression data using real-time quantitative PCR and the 2(-Delta Delta C(T)) Method. Methods 25:402-408.

Loza-Correa. M, Juan A. Ayala, Iris Perelman, Keith Hubbard, Miloslav Kalab, QiLong Yi, Mariam Taha, Miguel A. de Pedro, and Ramirez-Arcos S. 2019. The peptidoglycan and biofilm matrix of Staphylococcus epidermidis undergo structural changes when exposed to human platelets. PLOS ONE 14:e0211132.

Machado A, Almeida C, Carvalho A, Boyen F, Haesebrouck F, Rodrigues L, Cerca N, and Azevedo NF. 2013. Fluorescence in situ hybridization method using a peptide nucleic acid probe for identification of Lactobacillus spp. in milk samples. Int J Food Microbiol 162:6470.

Malachowa N, Whitney AR, Kobayashi SD, Sturdevant DE, Kennedy AD, Braughton KR, Shabb DW, Diep BA, Chambers HF, Otto M, and DeLeo FR. 2011. Global Changes in Staphylococcus aureus Gene Expression in Human Blood. PLOS ONE 6:e18617.

Mereghetti L, Sitkiewicz I, Green NM, and Musser JM. 2008. Extensive Adaptive Changes Occur in the Transcriptome of Streptococcus agalactiae (Group B Streptococcus) in Response to Incubation with Human Blood. PLOS ONE 3:e3143.

Miles AA, Misra SS, and Irwin JO. 1938. The estimation of the bactericidal power of the blood. Journal of Hygiene 38:732-749.

Nolte O, Rickert A, Ehrhard I, Ledig S, and Sonntag HG. 2002. A modified ex vivo human whole blood model of infection for studying the pathogenesis of Neisseria meningitidis during septicemia. FEMS Immunology Medical Microbiology 32:91-95.

Nordahl EA, Rydengård V, Nyberg P, Nitsche DP, Mörgelin M, Malmsten M, Björck L, and Schmidtchen A. 2004. Activation of the complement system generates antibacterial peptides. Proceedings of the National Academic of Science of U S A 101:16879-16884. 
361 Opota O, Croxatto A, Prod'hom G, and Greub G. 2015. Blood culture-based diagnosis of

362

363

364

365

366

367

368

369

370

371

372

373

374

375

376

377

378

379

380

381

382 bacteraemia: state of the art. Clinical Microbiology Infection 21:313-322.

Otto M. 2009. Staphylococcus epidermidis--the 'accidental' pathogen. Nature Reviews Microbiology 7:555-567.

Pfaffl MW. 2004. Quantification strategies in real time PCR. A-Z of quantitative PCR. S.A. Bustin ed. La Jolla, CA, USA: International University Line, 87-112.

Qin L, Da F, Fisher EL, Tan DC, Nguyen TH, Fu CL, Tan VY, McCausland JW, Sturdevant DE, Joo HS, Queck SY, Cheung GY, and Otto M. 2017. Toxin Mediates Sepsis Caused by Methicillin-Resistant Staphylococcus epidermidis. PLOS Pathogens 13:e1006153.

Strobel L, and Johswich KO. 2018. Anticoagulants impact on innate immune responses and bacterial survival in whole blood models of Neisseria meningitidis infection. Sci Rep 8:10225.

Untergasser A, Cutcutache I, Koressaar T, Ye J, Faircloth BC, Remm M, and Rozen SG. 2012. Primer3--new capabilities and interfaces. Nucleic Acids Research 40:22.

Vebo HC, Snipen L, Nes IF, and Brede DA. 2009. A modifed ex vivo human whole blood model of infection for studying the pathogenesis of Neisseria meningitidis during septicemia. PLOS ONE 4.

Whitney AR, Diehn M, Popper SJ, Alizadeh AA, Boldrick JC, Relman DA, and Brown PO. 2003. Individuality and variation in gene expression patterns in human blood. Proceedings of the National Academy of Sciences 100:1896-1901. 


\section{Table 1 (on next page)}

List of primers used for the quantification of gene expression by qPCR 
1 Table 1. List of primers used for the quantification of gene expression by qPCR

\begin{tabular}{|c|c|c|c|}
\hline Gene & Primer sequence $\left(5^{\prime}-3^{\prime}\right)$ & $\begin{array}{c}\text { Product } \\
\text { size } \\
\text { (base pair) }\end{array}$ & $\begin{array}{c}\text { Efficiency } \\
(\%)\end{array}$ \\
\hline $\begin{array}{c}S E R P_{-} R S 00125 \\
(16 \bar{S} r R N A)\end{array}$ & $\begin{array}{l}\text { Fw: GGGCTACACACGTGCTACAA } \\
\text { Rv: GTACAAGACCCGGGAACGTA }\end{array}$ & 176 & 97 \\
\hline$S E R P \_R S 11970$ & $\begin{array}{l}\text { Fw: CAGGCATTGAACTTCCCAAT } \\
\text { Rv: AATTCGGGGGCATATTTAGG }\end{array}$ & 109 & 103 \\
\hline SERP_RS10985 & $\begin{array}{l}\text { Fw: ATGATTTTAGTGCTATCCCTGACT } \\
\text { Rv: CACTAATTGCAAGATCATTTTCTG }\end{array}$ & 102 & 110 \\
\hline $\begin{array}{c}\text { SERP_RS08870 } \\
(\operatorname{sep} A)\end{array}$ & $\begin{array}{l}\text { Fw: TCTTAAGGCATCTCCGCCTA } \\
\text { Rv: GTCTGGTGCGAATGATGTTG }\end{array}$ & 196 & 97 \\
\hline
\end{tabular}


Figure 1

The effect of initial bacterial concentrations on the ability of $S$. epidermidis to survive in human blood after $4 \mathrm{~h}$ and $8 \mathrm{~h}$ of incubation.

The bars represent the mean plus standard deviation of five independent experiments, performed with five different donors. Statistical analysis was performed using two-way ANOVA and Tukey's multiple comparisons test.

Significant differences between $10^{8}$ and the other bacterial concentrations are depicted with ${ }^{* *} p<0.01 ; * * * p<0.001 ; * * * *<0.0001$.

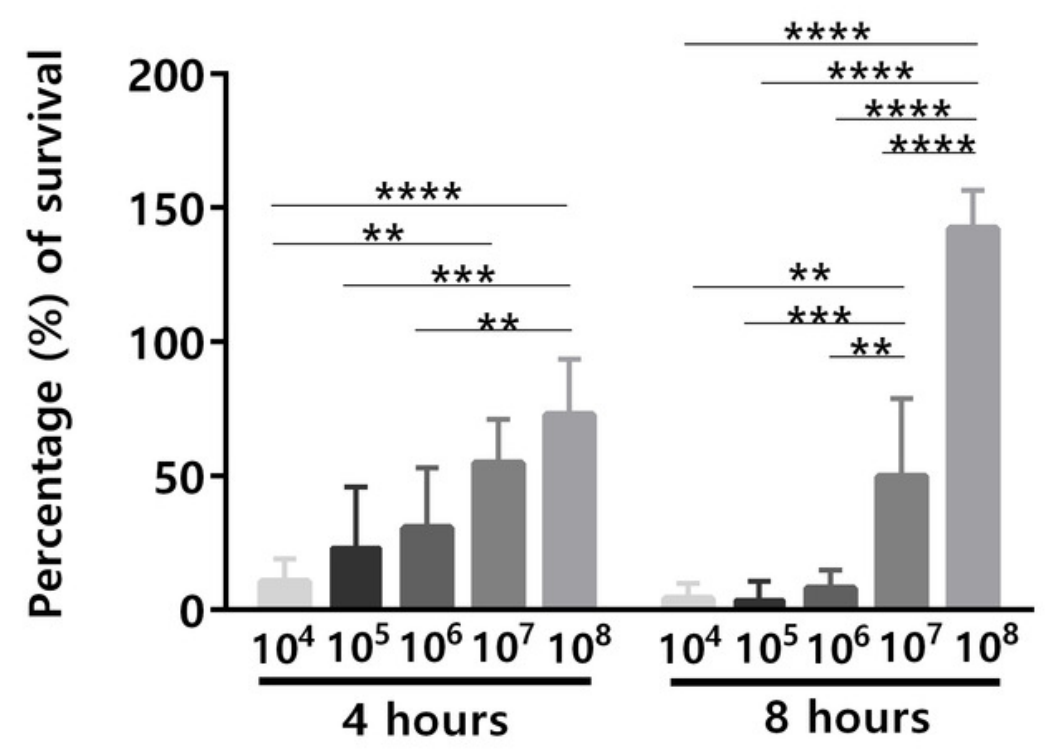




\section{Figure 2}

The influence of time after blood collection on bacterial survivability and leukocyte viability.

(A) Bacterial survivability after $4 \mathrm{~h}$ of co-incubation with blood. Bacteria was added to blood immediately after collection or $4 \mathrm{~h}$ post-blood collection. Bacterial survivability was determined by CFU counting. The bars represent the mean plus standard deviation of three independent experiments, performed using three different donors. (B)Viability of human blood leukocytes after collection. Leukocytes viability was assessed by flow cytometry immediately, 4 and $8 \mathrm{~h}$ after blood collection, before utilization in the co-incubation assays. The bars represent the mean plus standard deviation of three independent experiments, performed using three different donors. Statistical analysis was performed using one-way ANOVA and Tukey's multiple comparison test. ${ }^{*} p<0.05 .{ }^{* *} p<0.01$.

(A)

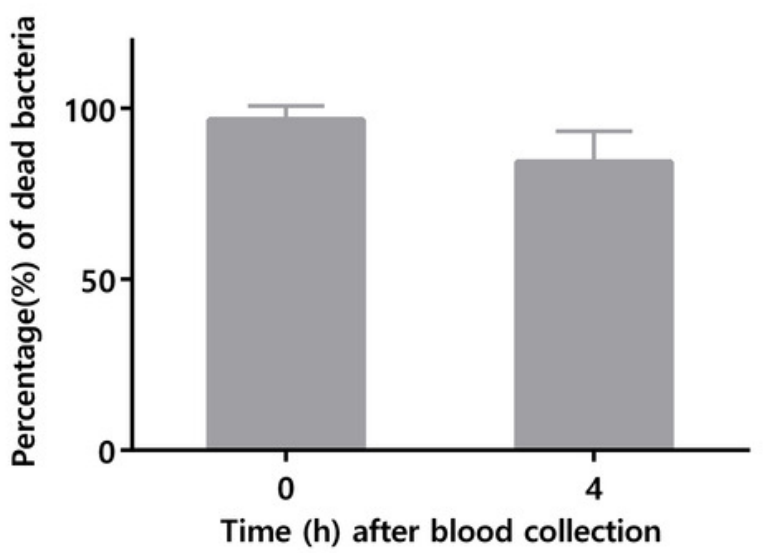

(B)

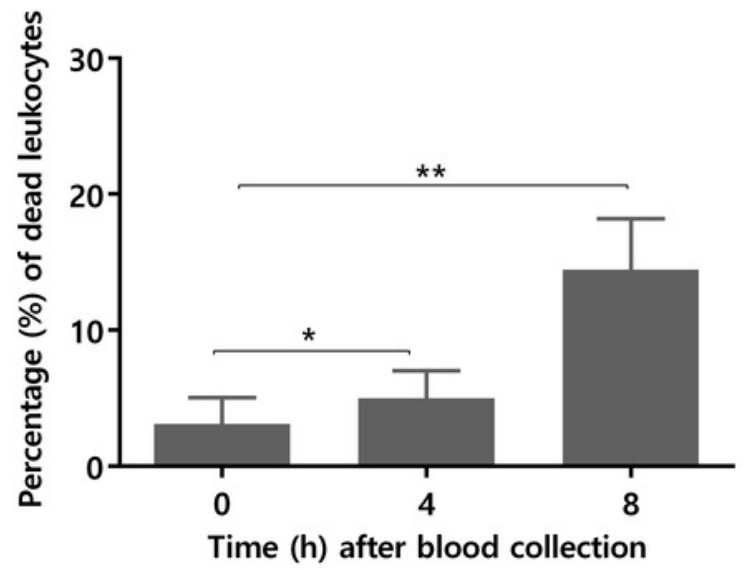


Figure 3

The influence of using different volumes of human blood in co-incubations assays on the stability of transcription levels of SERP_RS11970, SERP_RS10985 and SERP_RS08870 genes.

Bacteria was added to each tube to obtain a final concentration of $10^{8} \mathrm{CFU} / \mathrm{mL}$ and then the tubes were incubated for $2 \mathrm{~h}$ at $37^{\circ} \mathrm{C}$. The bars represent the mean plus standard deviation of normalized expression of three independent experiments, performed with three different donors. Statistical analysis was performed, respectively, using one-way ANOVA and Tukey's multiple comparisons test.

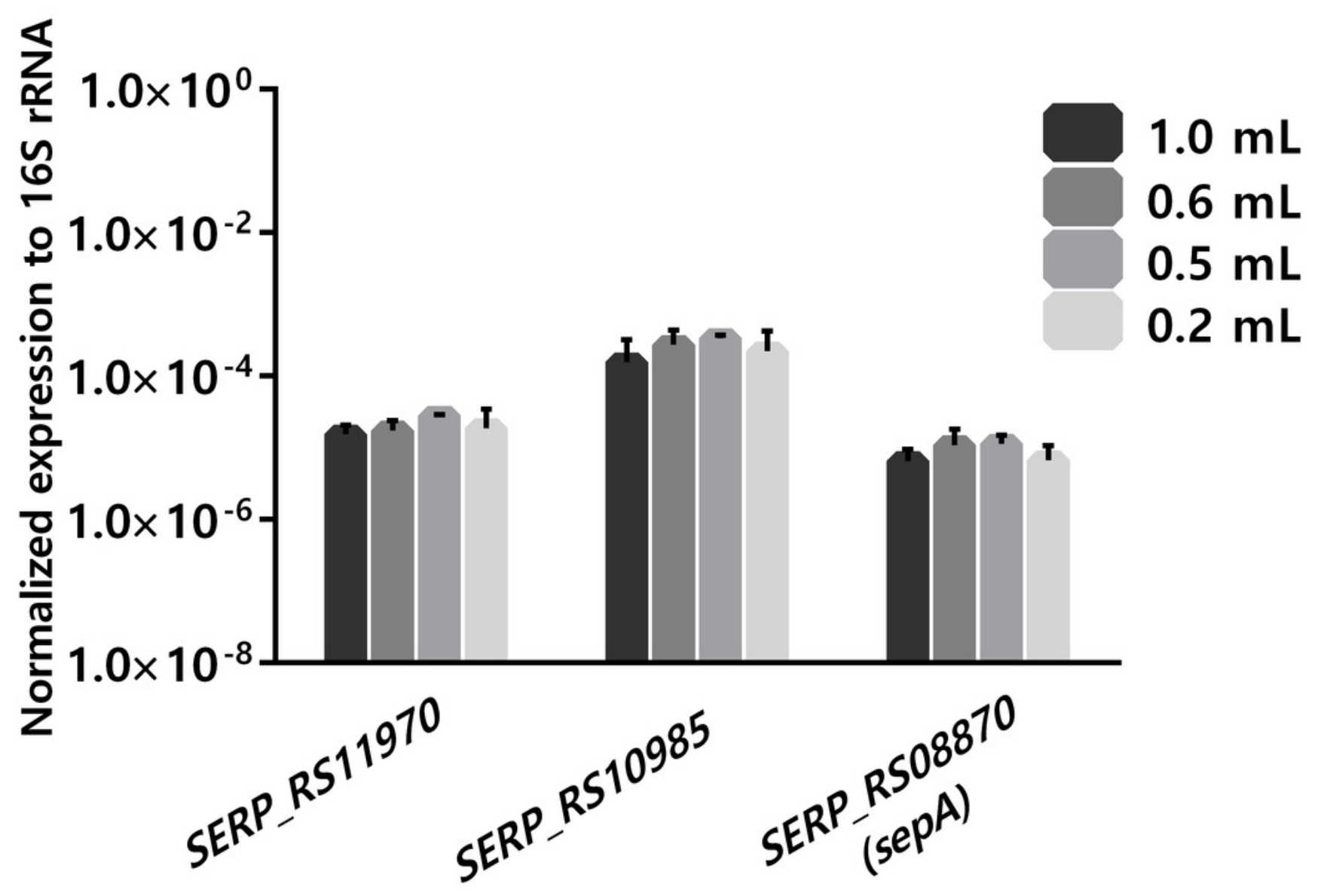

